\title{
Stator Design of Alternate Slot Winding for Reducing Torque Pulsation with Magnet Designs in Surface-Mounted Permanent Magnet Motors
}

\author{
Yuichi Yoko, Member, IEEE, Tsuyoshi Higuchi, Member, IEEE
}

\begin{abstract}
This paper proposes a stator design that consists of a combination of an alternate slot winding and dummy slots to minimize pulsating torque in surface-mounted permanent magnet (PM) synchronous motors. The alternate arrangement of winding coils is designed to eliminate a harmonic component of back-EMF that gives rise to a harmonic component of pulsating torque. However, the non-uniform arrangement of slots decreases the frequency of the cogging torque by half and may aggravate torque pulsation. To compensate for the drawback or the decrease in the frequency of the cogging torque, dummy slots are introduced in the alternately slotted stator. A theoretical method is developed for the proposed stator combination. The proposed stator design is applied to a prototype in combination with other rotor magnet design techniques, such as magnet shifting and the adjustment of magnet width, to minimize pulsating torque. The results show that the designed motor reduces the ripple factor of the torque by approximately $30 \%$ relative to the original value. In addition, the proposed alternate slot winding is validated by comparing the design with equal slot winding designs optimized through FEM analysis.
\end{abstract}

Index Terms-alternate slot winding, dummy slots, pulsating torque, ripple torque, cogging torque

\section{INTRODUCTION}

$\mathbf{T}$ ORQUE smoothness is an important capability of electrical machines in high-performance motion control applications. Although the use of permanent magnets (PMs) provides synchronous motors with favorable power densities, torque-inertia ratios, and electrical efficiencies, torque pulsation develops into a considerable problem for applications. The arrangement of stator winding coils and rotor magnet blocks imposes spatial harmonics on the density distribution of the air-gap flux. The harmonic components give rise to torque pulsation with vibration and acoustic noise during operation [1].

To reduce pulsating torque, a wide variety of design techniques have been proposed and applied to electrical machines [2]-[22]. In these techniques, the stator slot winding is arranged for various purposes, including the reduction of harmonics in the spatial distribution of the air-gap flux density [4]. Because coil sides are inserted into slots, the slot winding arrangement is strongly dependent on the numbers of coils and slots. To increase the number of possible slot winding arrangements with fixed numbers of coils and

Y. Yokoi is with the Division of Electrical Engineering and Computer Science, Nagasaki University, 1-14 Bunkyo, Nagasaki, 852-8521 Japan email: yyokoi@nagasaki-u.ac.jp.

T. Higuchi is with Nagasaki University.

Manuscript received April xx, 20xx; revised December xx, 20xx. slots, several design techniques have been developed. For a distributed winding, the number of conductors is determined for each slot in a so-called graded winding [1]. Graded windings are improved by the introduction of a non-uniform slot distribution [5]. Each end coil side of one phase group in a distributed winding is interchanged with the corresponding coil side from the adjacent phase group, called an interspersed winding [6]. With the connection of polyphase windings, star-delta mixed connection is proposed in parallel [7] or in series [8]. These techniques are effective for large numbers of coils and slots. However, such large numbers of coils and slots lead to complexity during fabrication due to the winding of many coils into narrow slots in small machines. Therefore, the slot winding arrangement for small numbers of coils and slots may provide no favorable harmonic rejection in the air-gap flux density distribution without incorporating any other designs. For rotor magnet blocks, several design techniques, each of which can selectively eliminate a harmonic component [2], [3], [9]-[13], are simultaneously employed to achieve harmonic rejection [9], [10], [12], [13]. In terms of the selective elimination of harmonics, the slot winding arrangement, such as that in which the slot winding is nonuniformly distributed [5], can be applied to stators with a small number of slots in combination with rotor magnet designs.

This paper describes a stator design suited for the selective elimination of a harmonic component in the air-gap flux density distribution for reducing pulsating torque in surfacemounted PM synchronous motors. Minimization of the pulsating torque is achieved by selectively eliminating the lowest harmonic components due to the stator design and several rotor magnet designs. The proposed stator design consists of an alternate arrangement of stator slots and coils and the introduction of dummy slots. The alternate slot winding scheme corresponds to the simplest arrangement of nonuniformly distributed slot windings [5] at 2 slots per pole per phase. An alternate arrangement of stator slots doubles the period in the spatial distribution of magnetic reluctance. Hence, the frequency of the cogging torque decreases by half. This reduced frequency may aggravate torque pulsation. To compensate for the aggravated cogging torque, dummy slots [14], [15], which have the opposite effect, are introduced in the alternately slotted stator. The dummy slots are located such that each of the actual and dummy slots exhibits an identical distribution of magnetic reluctance.

The proposed stator combination design is validated through a finite element method (FEM) analysis of its torque produc- 
tion for an appropriately designed rotor. The design method for the alternate slot winding is developed using a theoretical expression that has not previously been presented. All machine designs that feature an alternate slot winding scheme are based on theory. The designed machine exhibits better performance with respect to torque pulsation than do machines designed with an equal slot winding arrangement, even though the latter have been optimized through FEM analyses.

\section{Theoretical Guidelines For Minimizing PUlsating TORQue}

The minimization of pulsating torque is achieved by individually suppressing the harmonic components of the torque. Such suppression has previously been achieved by implementing the control schemes of selected harmonic injection [23]. The control schemes shape phase current waveforms by injecting selected harmonic components for desired pulsating torque cancellation. In this paper, each dominant harmonic component of pulsating torque is suppressed through the use of design techniques rather than control schemes.

In surface-mounted PM synchronous motors, pulsating torque can be divided into cogging and ripple torques based on the source [2]. Cogging torque is generated by the interaction of the rotor magnetic flux and the angular variation in the stator magnetic reluctance. Ripple torque corresponds to the pulsating component of the mutual torque produced by the interaction of the stator current's magnetomotive force with the rotor magnetic flux distribution. Thus, the minimization of pulsating torque is equivalent to the simultaneous suppression of the dominant harmonic components of cogging and ripple torques.

This section describes guidelines for theoretically designing or refining a motor to individually suppress its cogging and ripple torques. The theoretical formulation is developed for a $2 p$-pole, 3-phase surface-mounted PM synchronous motor, where $p$ indicates the number of pole pairs, assuming that magnetic saturation and losses are negligible.

\section{A. Cogging Torque Minimization}

To minimize the harmonic components of cogging torque, a wide variety of design techniques have been proposed, particularly for rotor magnets [2], [3]. For the slot arrangements of 3-phase integral slot windings, the cogging torque at the rotor position $\theta$ electrical can be expressed by the following Fourier series:

$$
\tau_{\mathrm{c}}(\theta)=\sum_{n=1}^{\infty} T_{\mathrm{c}, 6 n} \sin (6 n \theta),
$$

where $T_{\mathrm{c}, 6 n}$ is the coefficient. Because cogging torque is generally governed by several harmonic components, the minimization of cogging torque requires the simultaneous implementation of various design techniques, each of which suppresses one of the harmonics. Indeed, this approach may require the use of many different design techniques. However, only a few design techniques are required to minimize the cogging torque when the stator core shapes are well designed.

\section{B. Ripple Torque Minimization}

In contrast to cogging torque, ripple torque can be indirectly reduced by suppressing individual harmonic components of the back-EMF for a sinusoidal current supply. This suppression is theoretically confirmed by the power conversion of a given motor [24], as indicated below.

Based on the conversion from electrical power to mechanical power in the motor, the mutual torque at the rotor position $\theta$ electrical is given by

$$
\tau_{\mathrm{m}}(\theta)=\frac{p}{\omega}\left\{e_{\mathrm{u}}(\theta) i_{\mathrm{u}}(\theta)+e_{\mathrm{v}}(\theta) i_{\mathrm{v}}(\theta)+e_{\mathrm{w}}(\theta) i_{\mathrm{w}}(\theta)\right\},
$$

where $\omega$ denotes the electrical angular frequency and $e_{x}$ and $i_{x}$ are the back-EMF and the current of the $x$-phase winding, respectively. Because the cogging torque provides no contribution to the power conversion, it is not included in (2). The phase EMF can be expressed by the following Fourier series:

$$
e_{x}(\theta)=\sum_{m=1}^{\infty} E_{2 m-1} \cos \left[(2 m-1)\left(\theta-\varphi_{x}\right)\right],
$$

where $E_{2 m-1}$ is the coefficient and $\varphi_{x}$ is the position of the $x$-phase winding axis. No even-order harmonics are included in the EMF because of the symmetrical design with respect to the pole pair. For the $x$-phase EMF, the $x$-phase current is regulated as follows:

$$
i_{x}(\theta)=\sqrt{\frac{2}{3}} I \sin \left(\theta-\varphi_{x}+\theta_{0}\right),
$$

where $\theta_{0}$ is the current phase. The fed current enhances the flux of the magnets at $\theta_{0}=0^{\circ}$ and maximizes the average torque at $\theta_{0}=90^{\circ}$. The EMF and the current of the 3 phases are determined by 3-phase symmetry. By substituting the 3phase EMF and current into (2), the mutual torque is

$$
\tau_{\mathrm{m}}(\theta)=\sqrt{\frac{3}{2}} \frac{p}{\omega} \sum_{n=-\infty}^{\infty} E_{6 n-1} I \sin \left(6 n \theta+\theta_{0}\right) .
$$

Here, the relation $E_{-6 n-1}=E_{6 n+1}$ is defined. The mutual torque consists of a constant and $6 n$-th harmonics, corresponding to ripple torques:

$$
\tau_{\mathrm{m}}(\theta)=T_{0} \sin \theta_{0}+\sum_{n=1}^{\infty} T_{\mathrm{r}, 6 n} \sin \left(6 n \theta+\theta_{\mathrm{r}, 6 n}\right),
$$

where $T_{0}$ and $T_{\mathrm{r}, 6 n}$ denote the amplitude and $\theta_{\mathrm{r}, 6 n}$ denotes the phase difference. The components are expressed as

$$
T_{0}=\sqrt{\frac{3}{2}} \frac{p}{\omega} E_{1} I
$$

and

$$
\begin{aligned}
T_{\mathrm{r}, 6 n} \sin \left(6 n \theta+\theta_{\mathrm{r}, 6 n}\right)= & \sqrt{\frac{3}{2}} \frac{p}{\omega} E_{6 n-1} I \sin \left(6 n \theta+\theta_{0}\right) \\
& -\sqrt{\frac{3}{2}} \frac{p}{\omega} E_{6 n+1} I \sin \left(6 n \theta-\theta_{0}\right) .
\end{aligned}
$$

The $3 n$-th harmonic components of the EMF provide no contribution to the production of torque because of the 3-phase symmetry. Equation (8) demonstrates that the $6 n$-th harmonics 


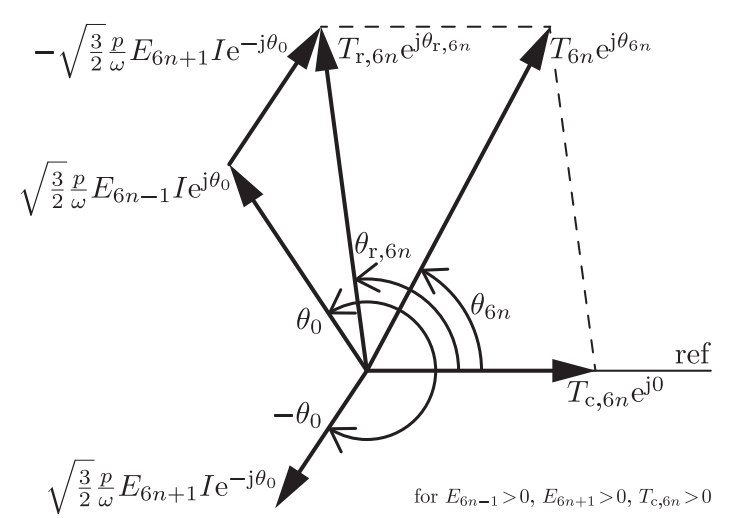

Fig. 1. Phasor diagram for a harmonic component of torque.

of the ripple torque is caused by the $(6 n-1)$-th and $(6 n+1)$-th harmonics of the EMF.

Figure 1 shows the phasor diagram for the relationship between the $(6 n \pm 1)$-th harmonic components of the EMF and the $6 n$-th harmonic component of the ripple torque as well as the corresponding harmonic component of the total torque $T_{6 n}$, which is the sum of the ripple torque $T_{\mathrm{r}, 6 n}$ and the cogging torque $T_{\mathrm{c}, 6 n}$. Based on this relationship, the ripple torque can be minimized by suppressing the $(6 n \pm 1)$-th harmonics of the EMF, except for the fundamental harmonic. Equation (8) indicates that the magnitudes of the harmonics of the ripple torque are dependent on those of the 2 corresponding harmonics of the EMF. For this reason, the ripple torque can be effectively minimized by suppressing the dominant harmonics of the EMF.

\section{Proposed Stator Combination Design}

A stator design that meets the described design guidelines is proposed. The proposed design consists of the slot winding arrangement that eliminates a harmonic component of the EMF and the introduction of dummy slots that reduce the number of harmonic components of the cogging torque.

\section{A. Alternate Slot Winding Arrangement}

To eliminate a harmonic component of the back-EMF induced in the phase winding, an alternate slot winding arrangement is proposed for a stator structure slotted with 2 slots per pole per phase. The arrangement possesses a symmetry or a periodicity with respect to each phase winding to produce no additional harmonics in the mutual torque. For each pole, the 2 coil sides of a phase winding are embedded in 2 adjacent slots. The mutual position of the slots or the embedded coil sides is adjusted to selectively eliminate a harmonic component of the EMF. This configuration implies a stator that is alternately slotted at wide and narrow intervals. In this paper, this arrangement is referred to as the alternate arrangement.

The angle between 2 adjacent slots or coils is determined to eliminate a harmonic component of the EMF. For each pole pair, 2 coils of a phase winding are located at an angular distance of $\alpha_{\mathrm{s}}\left(<30^{\circ}\right)$ electrical, called the slot angle, from

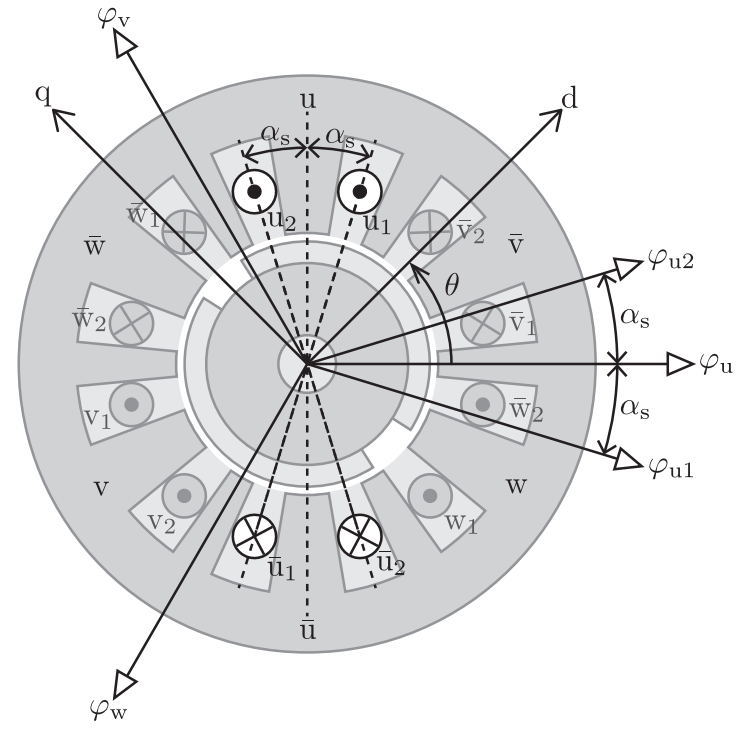

Fig. 2. Frame reference.

the center of the phase winding, as shown in Fig. 2. The slot angle $\alpha_{\mathrm{s}}$ corresponds to half of the angular width between 2 adjacent slots containing coil sides of a phase winding, namely the slots $\mathrm{u}_{1}$ and $\mathrm{u}_{2}$ or $\overline{\mathrm{u}}_{1}$ and $\overline{\mathrm{u}}_{2}$ for the u-phase winding. In Fig. 2, for the $x$-phase winding, $\varphi_{x}, \varphi_{x 1}$, and $\varphi_{x 2}$ denote the axes of the phase winding and the 2 coils, respectively.

The back-EMF induced in a coil identified by the axis $\varphi$ electrical can be expressed by the following Fourier series:

$$
e_{\text {coil }}(\theta ; \varphi)=\sum_{n=1}^{\infty} E_{2 n-1}^{\prime} \cos [(2 n-1)(\theta-\varphi)],
$$

where $E_{2 n-1}^{\prime}$ is the harmonic amplitude. Using this equation, the back-EMF induced in the $x$-phase winding is given by

$$
\begin{aligned}
e_{x}(\theta) & =p\left\{e_{\text {coil }}\left(\theta ; \varphi_{x 1}\right)+e_{\text {coil }}\left(\theta ; \varphi_{x 2}\right)\right\} \\
& =p\left\{e_{\text {coil }}\left(\theta ; \varphi_{x}-\alpha_{\mathrm{s}}\right)+e_{\text {coil }}\left(\theta ; \varphi_{x}+\alpha_{\mathrm{s}}\right)\right\} \\
& =\sum_{n=1}^{\infty} 2 p k_{\mathrm{w}, 2 n-1} E_{2 n-1}^{\prime} \cos \left[(2 n-1)\left(\theta-\varphi_{x}\right)\right],
\end{aligned}
$$

where the winding factor is expressed by

$$
k_{\mathrm{w}, \nu}=\cos \left(\nu \alpha_{\mathrm{s}}\right) .
$$

In (10), a phase winding consists of series-connected phase coils. In this case, the amplitude of the $\nu$-th harmonic component is $E_{\nu}=2 p k_{\mathrm{w}, \nu} E_{\nu}^{\prime}$. Equations (10) and (11) imply that the $\nu$-th harmonic component of the EMF is eliminated by adjusting the slot angle to

$$
\alpha_{\mathrm{s}}=\frac{90^{\circ}(2 i-1)}{\nu}
$$

for a positive integer $i$. The winding factor $k_{\mathrm{w}, \nu}$ of (11) at the equal slot pitch $\alpha_{\mathrm{s}}=15^{\circ}$ is equivalent to the distribution factor $k_{\mathrm{d}, \nu}$ for $q(=2)$ slots per pole per phase expressed by

$$
k_{\mathrm{d}, \nu}=\frac{\sin \left(90^{\circ} \nu / m\right)}{q \sin \left(90^{\circ} \nu / m q\right)},
$$

where $m$ denotes the number of phases. The values of the factors are presented in Table I. 
TABLE I

WINDING FACTORS FOR THE SLOT ANGLE $\alpha_{\mathrm{S}}$

\begin{tabular}{crrr}
\hline & \multicolumn{2}{c}{ Eq. (11) } & Eq. (13) \\
order & $\alpha_{\mathrm{s}}=15^{\circ}$ & $\alpha_{\mathrm{s}}=18^{\circ}$ & $q=2$ \\
\hline 1 & 0.9659 & 0.9511 & 0.9659 \\
5 & 0.2588 & 0 & 0.2588 \\
7 & -0.2588 & -0.5878 & -0.2588 \\
11 & -0.9659 & -0.9511 & -0.9659 \\
13 & -0.9659 & -0.5878 & -0.9659 \\
17 & -0.2588 & 0.5878 & -0.2588 \\
19 & 0.2588 & 0.9511 & 0.2588 \\
\hline
\end{tabular}

(a)

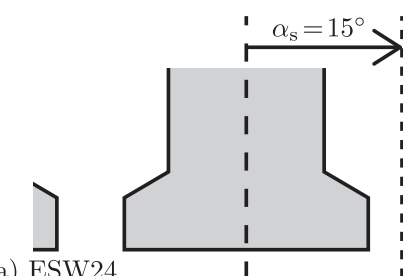

a) $\operatorname{ESW} 24$

b) $\overrightarrow{\mathrm{ESW}} 48$

(c) $\operatorname{ESW} 72$
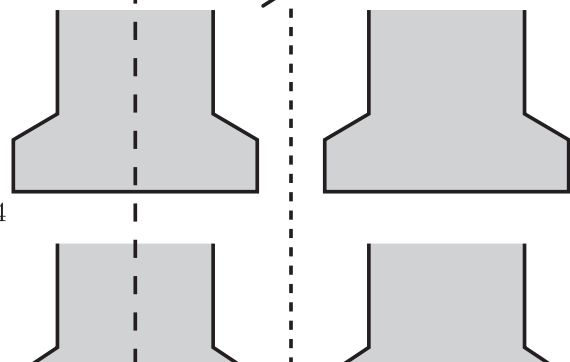

(d) ASW24

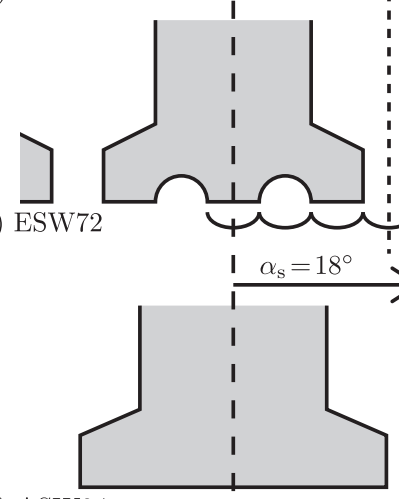

I

(e) ASW60

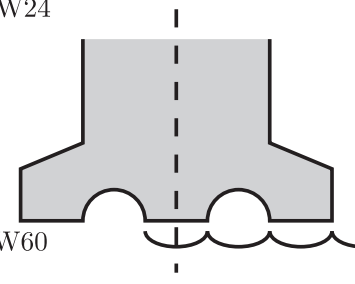

Fig. 3. Arrangements of actual slots and dummy slots for equal and alternate slot windings. The angles are indicated in electrical degrees.

\section{B. Dummy Slots}

The alternate arrangement of stator slots doubles the number of harmonic components in the cogging torque although this arrangement can eliminate a harmonic component of the backEMF. The orders of the added harmonics are half of the lowest order and odd multiples thereof because each pair of adjacent teeth establishes one period of the spatially periodic distribution of slot openings, as the arrangement at $\alpha_{\mathrm{s}}=18^{\circ}$ shown in Fig. 3(d). According to the theoretical guidelines established in the previous section, the minimization of the cogging torque requires the suppression of all harmonic com-
TABLE II

DIMENSIONS OF THE ANALYZED MOTOR.

\begin{tabular}{lr}
\hline Stator core length & $50 \mathrm{~mm}$ \\
Squared stator side length & $125 \mathrm{~mm}$ \\
Air gap length & $1 \mathrm{~mm}$ \\
Rotor outer diameter & $67.1 \mathrm{~mm}$ \\
Magnet thickness & $6 \mathrm{~mm}$ \\
Magnetization direction & Parallel \\
Number of turns per coil & 50 \\
\hline
\end{tabular}

ponents with large amplitudes. Therefore, the alternate slot arrangement may make it difficult to minimize the cogging torque. In addition, the added harmonics may increase the peak value of the cogging torque.

Dummy slots compensate for the drawback of the alternate slot arrangement. In general, the dummy slots are introduced in stator teeth to establish their slot openings, which are magnetically equivalent to those of the actual slots, and the slot opening width of the actual and dummy slots are adjusted to half the slot pitch. As a result, the dummy slots suppress the lowest harmonics and produce a prominent harmonic component of higher order. Figs. 3(b) and (c) show examples of the introduction of dummy slots in teeth of equal width. For teeth of alternating width, dummy slots can be introduced as follows. In the alternate slot winding for $\nu$-th harmonic EMF elimination, the 2 slot pitches are $2 \alpha_{\mathrm{S}}\left(=180^{\circ}(2 i-1) / \nu\right)$ and $60^{\circ}-2 \alpha_{\mathrm{s}}$. The ratio of the pitches is $3(2 i-1):(\nu-3(2 i-1))$, and the integers $3(2 i-1)$ and $(\nu-3(2 i-1))$ correspond to the number of periodic distributions of magnetic reluctance to be established in the pitches between the actual slots. Therefore, the numbers of dummy slots introduced in the teeth between the slots at a distance of $2 \alpha_{\mathrm{s}}$ and $60^{\circ}-2 \alpha_{\mathrm{s}}$ are $3(2 i-1)-1$ and $\nu-3(2 i-1)-1$, respectively. The slot pitch is $60^{\circ} / \nu$, and the slot opening width is $30^{\circ} / \nu$. For example, for $\nu=5$, the arrangement of dummy slots is shown in Fig. 3(e). In this arrangement, the slot pitch is equal to $60^{\circ} / 5=12^{\circ}$ and the slot opening width is $30^{\circ} / 5=6^{\circ}$.

\section{Feasible Combination Design}

The combined stator design is constrained in terms of fabrication. The alternate slot winding used to eliminate an EMF harmonic of arbitrary order $\nu$ can be fabricated by selecting the integer $i$ in (12). On the other hand, the introduction of dummy slots for a higher order $\nu$ requires a narrower slot opening width, which makes winding the stator difficult. For this reason, the combined design is feasible for eliminating a lower-order harmonic component of the EMF, such as 5th or 7 th harmonic.

The combined stator design is herein employed to eliminate the 5th harmonic of the EMF. The slot angle is determined to be $90^{\circ} / 5=18^{\circ}$, and the slot opening width of the actual and dummy slots is $30^{\circ} / 5=6^{\circ}$. A schematic of the arrangement of the stator slots is shown in Fig. 3(e).

\section{EfFect of Proposed Stator Combination Design}

In this section, the combined stator design is validated through a FEM analysis. The analysis is performed for 3 


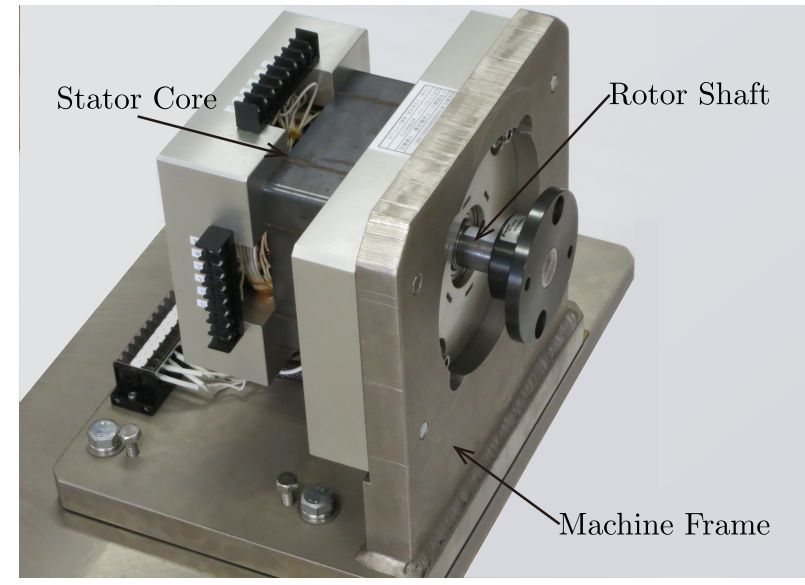

Fig. 4. Prototype surface-mounted PM synchronous motor.

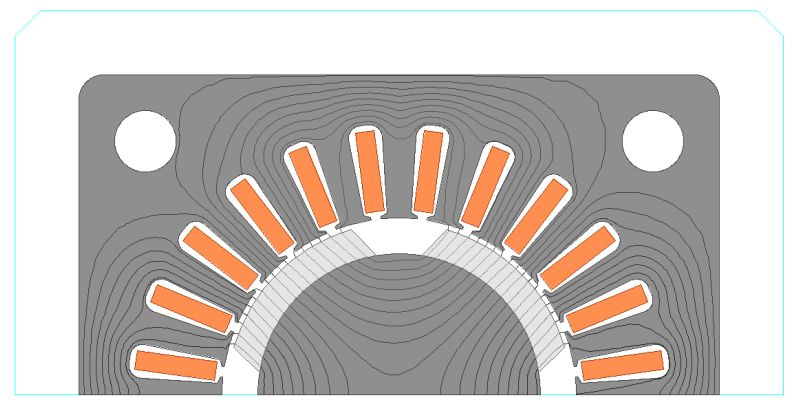

Fig. 5. Magnetic flux distribution in the finite element model of the prototype.

stator designs, namely, an equal slot winding arrangement, an alternate slot winding arrangement, and an alternate slot winding arrangement with dummy slots. These stator designs are designated ESW24, ASW24, and ASW60, respectively, and are shown in Fig. 3. The analyzed model for ESW24 is derived from a prototype, shown in Fig. 4, which is a 4-pole, 3-phase, and 24-slot surface-mounted PM synchronous motor with a single layer winding. The dimensions of the prototype are presented in Table II. Fig. 5 shows the magnetic flux distribution of the finite element model. The accuracy of the FEM analysis is confirmed by comparison with experimental results, as shown in Figs. 6, 7, and 12. In the prototype, as shown in Fig. 5, the square-shaped stator core is used to easily change the experimental setting. Although the shape of the stator causes additional harmonic components of pulsating torque, the components do not govern the torque pulsation. Therefore, the components are not considered in the stator design.

The back-EMF in the phase winding at $1500 \mathrm{rpm}$ for ESW24, ASW24, and ASW60 is shown in Fig. 6. The alternate slot winding designs substantially reduce the 5th harmonic component at the expense of increasing the 7 th and 17th harmonics. Complete elimination of the 5th harmonic component is prevented by magnetic saturation in ASW24. In fact, the arrangement with dummy slots, ASW60, exhibits a further reduction due to the decrease in the air-gap flux.

The cogging torque for the slot arrangements is shown in Fig. 7. The equal slot arrangement, ESW24, exhibits a

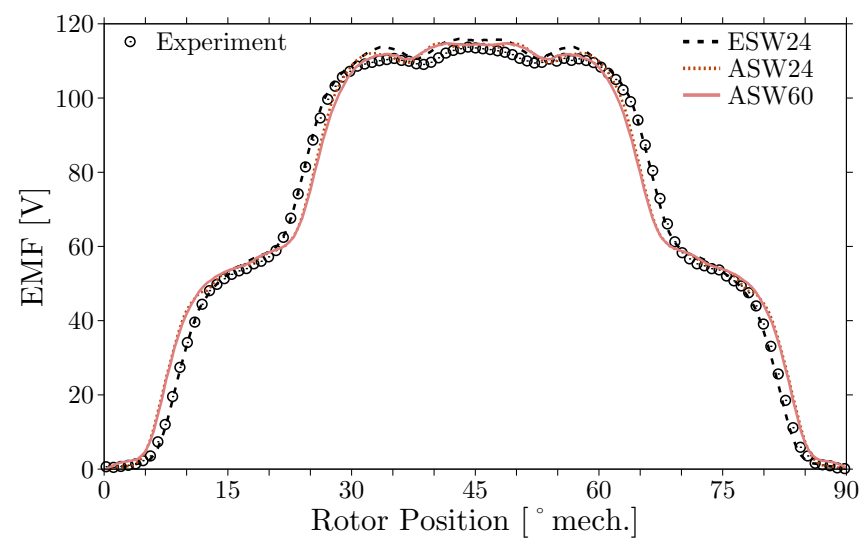

(a) Waveform.

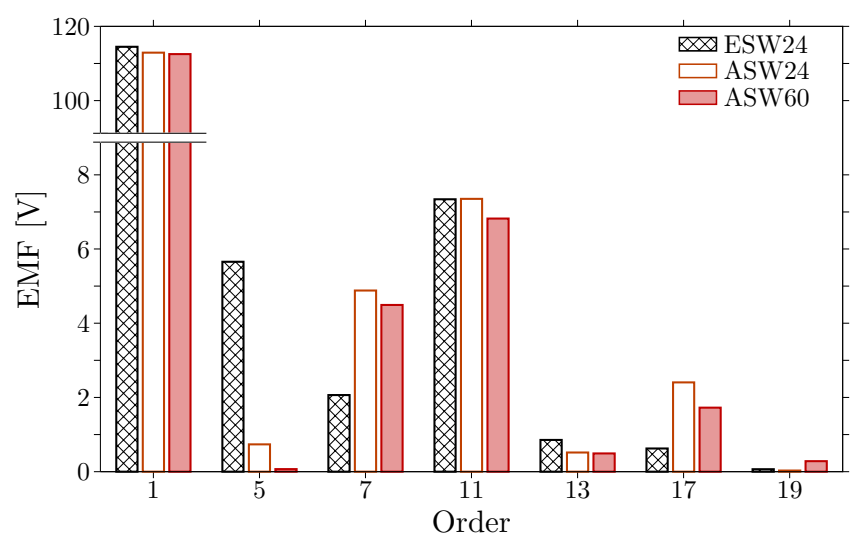

(b) Harmonic components.

Fig. 6. Back-EMF in phase winding at $1500 \mathrm{rpm}$ for ESW24, ASW24, ASW60.

dominant harmonic torque pulsation for each slot pitch, $15^{\circ}$. The cogging torque consists of harmonics whose order is a multiple of 12. On the other hand, the alternate slot arrangement, ASW24, includes harmonics whose order is an odd multiple of 6 . The resulting cogging torque has a slightly increased peak. The alternate slot arrangement with dummy slots, ASW60, shows a lower peak value than that of ESW24. As expected, the proposed arrangement suppresses the lowest 6th, 12th, 18th, and 24th harmonics and produces a prominent 30th harmonic component.

\section{Rotor Magnet Designs}

The combination of the alternate slot winding and the dummy slots substantially reduce the 5th harmonic of the EMF and the lowest harmonics of the cogging torque. The remaining harmonic components, in particular, the 7th and 11th harmonics of the EMF and the 30th harmonic of the cogging torque, must be sufficiently suppressed to minimize the pulsating torque. This suppression is achieved using two design techniques for rotor magnets, as shown in Fig. 8. The 7th harmonic of the EMF is suppressed by adjusting the arc width of the rotor magnets. The 30th harmonic of the cogging torque is minimized by shifting the positions of the magnets. In addition, the magnet shifting is well designed to 


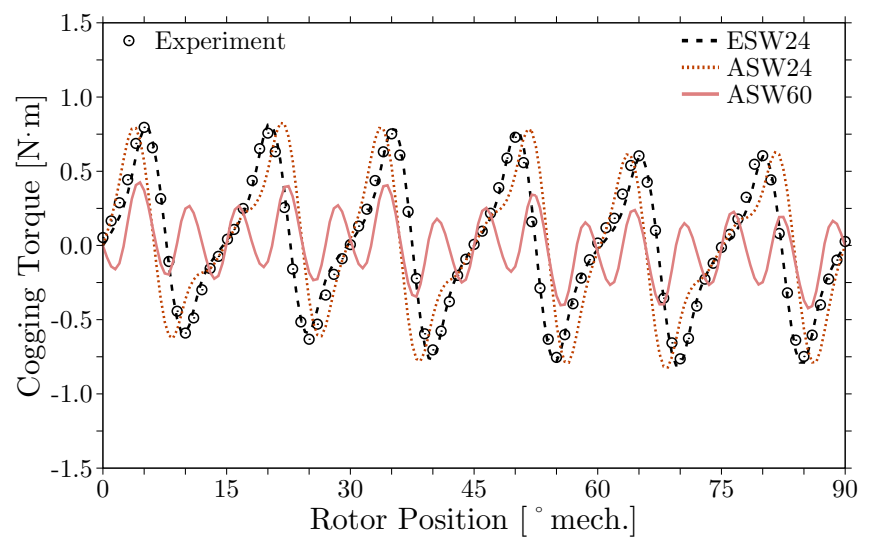

(a) Waveform.

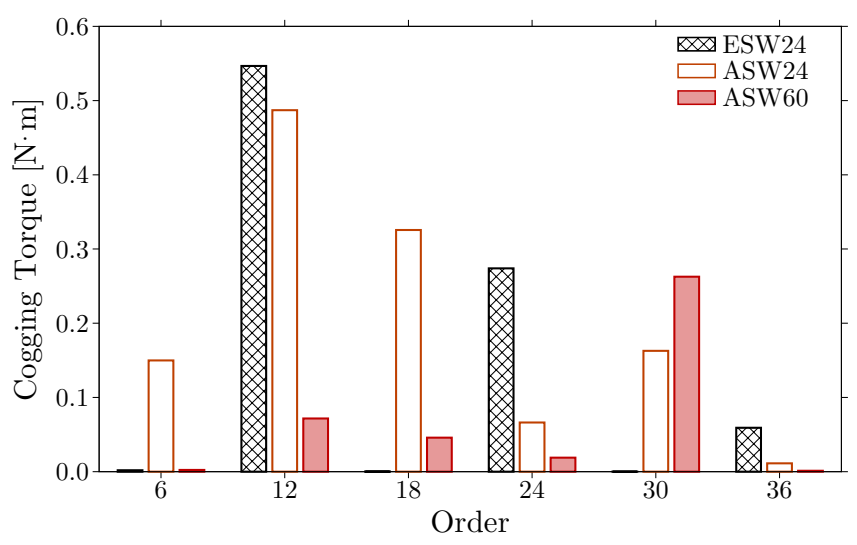

(b) Harmonic components.

Fig. 7. Cogging torque for ESW24, ASW24, ASW60.

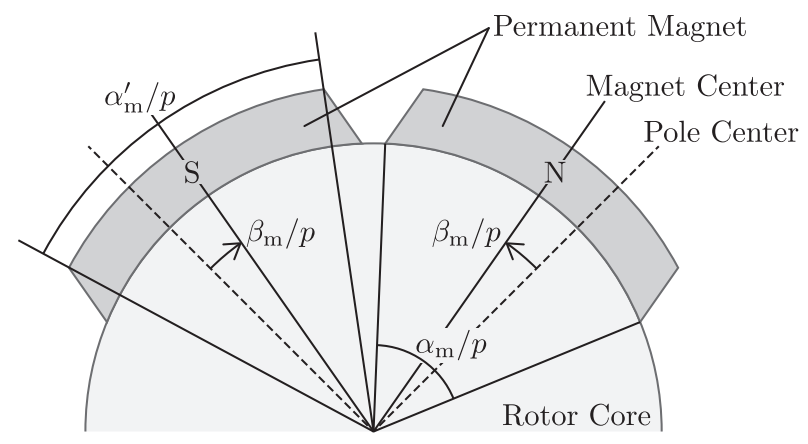

Fig. 8. Schematic design of PMs mounted on the rotor with the shift angle $\beta_{\mathrm{m}}$ and the magnet width $\alpha_{\mathrm{m}}$.

simultaneously reduce the 11th harmonic of the EMF.

\section{A. Magnet Shifting}

The mutual positions of the magnets on the rotor surface for each pole pair are adjusted to eliminate the dominant or 30th harmonic component of the cogging torque and to simultaneously reduce the 11th harmonic of the EMF. The technique of shifting magnet pairs was proposed to eliminate a harmonic component of the cogging torque [9]. As indicated in Ref. [3], the shift angle $\beta_{\mathrm{m}}$ electrical, defined in Fig. 8, for eliminating the $\nu$-th harmonic of the cogging torque is

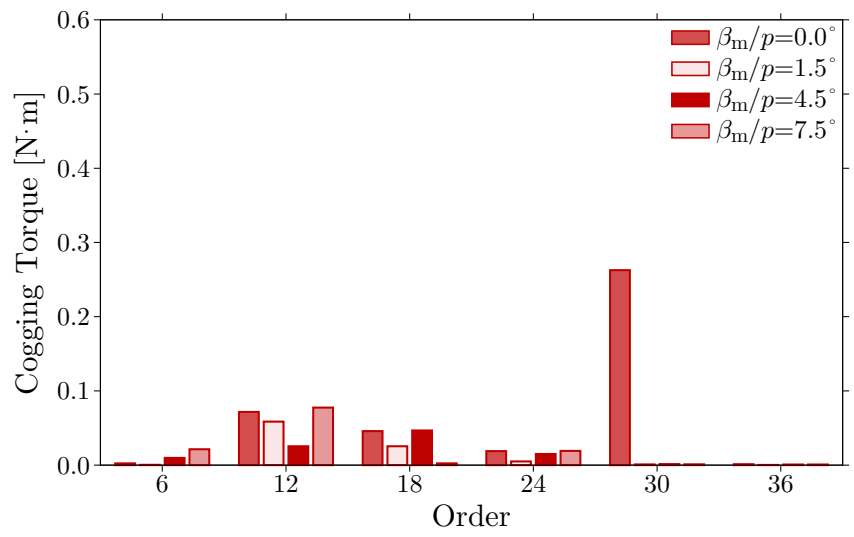

Fig. 9. Harmonic components of cogging torque for magnet shifting of $\beta_{\mathrm{m}}$ at $p=2$ and $\alpha_{\mathrm{m}} / p=71^{\circ}$ in ASW60.

theoretically determined to be

$$
\beta_{\mathrm{m}}=\frac{90^{\circ}(2 i-1)}{\nu}
$$

for a positive integer $i$. From (14), the 30th harmonic of the cogging torque can be eliminated by magnet shifting at $\beta_{\mathrm{m}} / p=1.5^{\circ}, 4.5^{\circ}, 7.5^{\circ}, \cdots$ for $p=2$. In general, the angle should be selected to be as small as possible to eliminate only one harmonic cogging torque because the magnet shifting at a large angle concentrates the radial force at the center of each pole pair, thereby enhancing vibration and noise and decreasing the fundamental EMF. In this paper, the shift angle is restricted to $\beta_{\mathrm{m}} / p \leq 9^{\circ}$, which is $10 \%$ of the pole pitch for $p=2$, to prevent the formation of a concentrated radial force.

Magnet shifting is also effective for the elimination of harmonic components of the EMF [3]. In addition to the elimination of a harmonic component of the cogging torque, magnet shifting can reduce a harmonic component of the EMF by selecting any but the smallest shift angle. The elimination of the 11th harmonic of the EMF requires magnet shifting with $\beta_{\mathrm{m}} / p=4.1^{\circ}$ from (14). This elimination is almost achieved by magnet shifting with $\beta_{\mathrm{m}} / p=4.5^{\circ}$ close to $\beta_{\mathrm{m}} / p=4.1^{\circ}$. The magnet shifting with $\beta_{\mathrm{m}} / p=4.5^{\circ}$, which is designed to eliminate the 30th harmonic of the cogging torque, cannot completely suppress the 11th harmonic of the EMF but is expected to significantly reduce the harmonic component. Therefore, magnet shifting is implemented at $\beta_{\mathrm{m}} / p=4.5^{\circ}$ to eliminate the 30th harmonic of the cogging torque and to significantly reduce the 11th harmonic of the EMF.

For the alternate slot arrangement with dummy slots, the cogging torque is reduced by magnet shifting at $p=2$ and $\alpha_{\mathrm{m}} / p=71^{\circ}$, as shown in Fig. 9. The magnet width $\alpha_{\mathrm{m}}$ is fixed at the value of the prototype. The magnet shifting almost completely eliminates the dominant or 30th harmonic components. Fig. 10 shows the effect of magnet shifting on the back-EMF in the phase winding at $p=2, \alpha_{\mathrm{m}} / p=72^{\circ}$, and $1500 \mathrm{rpm}$. As predicted, the 11th harmonic component can be significantly reduced by magnet shifting at $\beta_{\mathrm{m}} / p=4.5^{\circ}$. The 5th and 13th harmonic components remain small with the introduction of magnet shifting. 


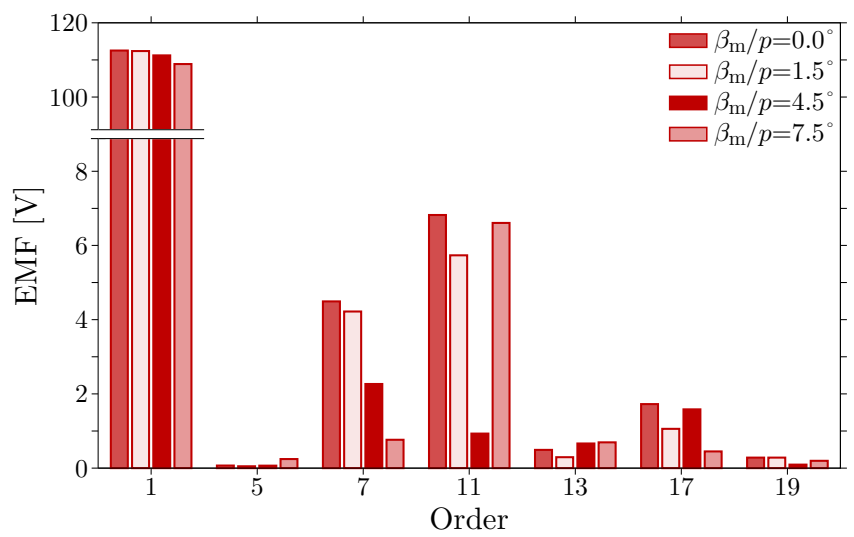

Fig. 10. Harmonic components of back-EMF in phase winding for magnet shifting of $\beta_{\mathrm{m}}$ at $p=2, \alpha_{\mathrm{m}} / p=71^{\circ}$, and $1500 \mathrm{rpm}$ in ASW60.

\section{B. Magnet Width}

The arc width of the magnets is adjusted to suppress the 7th harmonic of the EMF. The design method has been used to eliminate a harmonic component of the cogging torque [9] or EMF [3]. As indicated in Ref. [3], if the fringing field in the air gap is negligible, the magnet arc width $\alpha_{\mathrm{m}}^{\prime}$ electrical, defined in Fig. 8, for eliminating the $\nu$-th harmonic of the EMF is theoretically determined to be

$$
\alpha_{\mathrm{m}}^{\prime}=\frac{360^{\circ} i}{\nu}
$$

for a positive integer $i$. The maximum of the integer should be selected for a large fundamental harmonic of the EMF.

The magnet shape shown in Fig. 8 yields the relation $D_{\mathrm{m}} \sin \left(\alpha_{\mathrm{m}}^{\prime} / 2 p\right)=D_{\mathrm{r}} \sin \left(\alpha_{\mathrm{m}} / 2 p\right)$, where $D_{\mathrm{m}}$ and $D_{\mathrm{r}}$ denote the diameter of the rotor including the magnets and that of only the rotor core, respectively. Based on this relation, $\alpha_{\mathrm{m}}^{\prime} / p \leq 67.8^{\circ}$ because $\alpha_{\mathrm{m}} / p \leq 90^{\circ}$. By considering the ratio of torque production to fed current, the magnet width in this case is restricted to $\alpha_{\mathrm{m}} / p \geq 60^{\circ}$, that is, $\alpha_{\mathrm{m}}^{\prime} / p \geq 48.5^{\circ}$. Because the magnet shifting at $\beta_{\mathrm{m}} / p=4.5^{\circ}$ is used, the arc width of the rotor magnets is limited to $\alpha_{\mathrm{m}}^{\prime} / p<67.8^{\circ}-$ $2 \beta_{\mathrm{m}} / p=58.3^{\circ}$, corresponding to $\alpha_{\mathrm{m}}<81^{\circ}$. Equation (15) and the aforementioned limit determine the arc width of the magnets: $\alpha_{\mathrm{m}}^{\prime} / p=25.7^{\circ}$ and $51.4^{\circ}$. The larger magnet arc width, $\alpha_{\mathrm{m}}^{\prime} / p=51.4^{\circ}$, corresponding to $\alpha_{\mathrm{m}} / p=63.8^{\circ}$, is desirable in terms of torque production. Therefore, the angular width of the magnets is set to $\alpha_{\mathrm{m}} / p=64^{\circ}$.

Fig. 11 shows the back-EMF in the phase winding for a magnet width $\alpha_{\mathrm{m}}$ at $p=2, \beta_{\mathrm{m}} / p=4.5^{\circ}$, and $1500 \mathrm{rpm}$. It is confirmed that the 7 th harmonic is minimized in the vicinity of $\alpha_{\mathrm{m}} / p=63.8^{\circ}$. However, the precise magnet width for the minimized 7th harmonic is closer to $\alpha_{\mathrm{m}} / p=63^{\circ}$, which is attributed to the fringing field of the ends of the magnet blocks across the air gap. The suppression of the other harmonics is maintained.

\section{Confirmation of Pulsating Torque Minimization}

The minimization of the pulsating torque due to the proposed stator design with the design techniques used for rotor

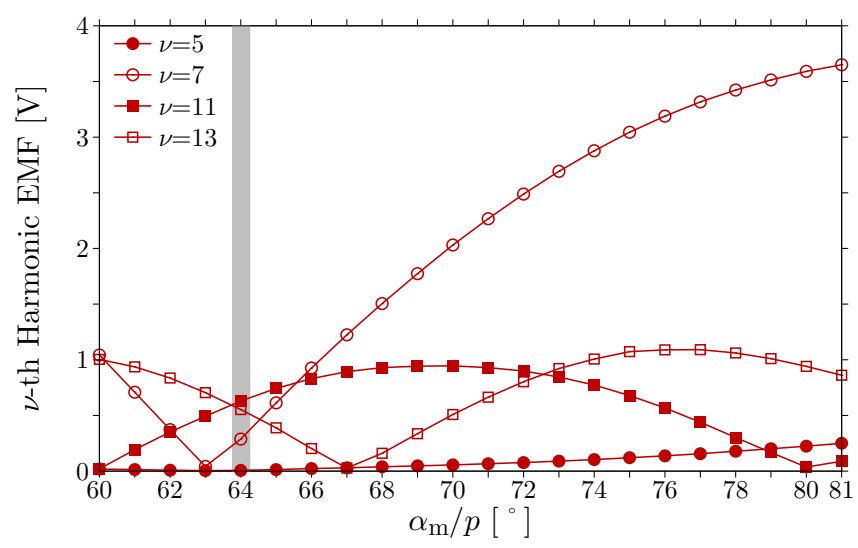

Fig. 11. Harmonic components of back-EMF in phase winding for a magnet width $\alpha_{\mathrm{m}}$ at $p=2, \beta_{\mathrm{m}} / p=4.5^{\circ}$, and $1500 \mathrm{rpm}$ in ASW60.

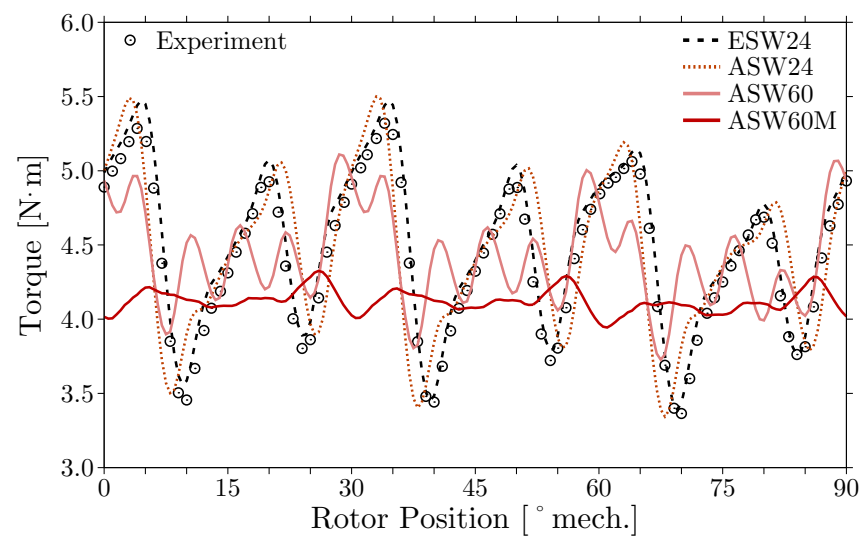

(a) Waveforms

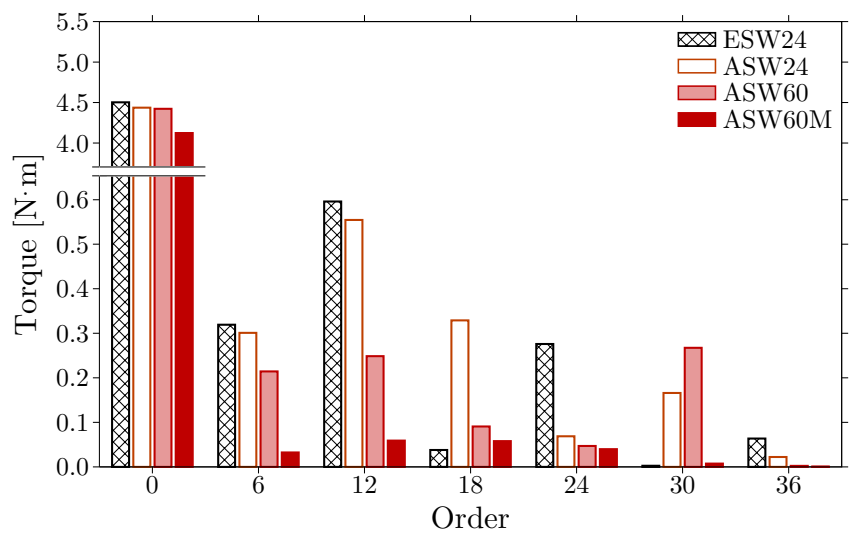

(b) Components.

Fig. 12. Torque for ESW24, ASW24, ASW60, and ASW60M. The fed current is fixed at the amplitude $I=5 \mathrm{~A}$ and the phase $\theta_{0}=90^{\circ}$ for vector control.

magnets, designated ASW60M, is confirmed by comparing with the minimization achieved for ESW24, ASW24, and ASW60. Fig. 12 shows the torque produced by the fed current with $I=5 \mathrm{~A}$ and $\theta_{0}=90^{\circ}$ for vector control. The remaining harmonic components to be suppressed in ASW60, namely, the 6th, 12th, and the 30th harmonics, are sufficiently reduced by the design techniques used for rotor magnets. Because the 5 th harmonic of the EMF and the 6th harmonic of the cogging 
torque have been eliminated by the alternate slot winding design, the 6th harmonic of the torque is suppressed by reducing the 7th harmonic of the EMF due to the adjustment of the magnet arc width. The 12th harmonic component is reduced with the decrease in the 11th harmonic of the EMF, which is dominant for the component. The 30th harmonic component caused by the cogging torque is eliminated by magnet shifting. In this manner, the proposed alternate slot winding with dummy slots can minimize the pulsating torque with the applied rotor magnet designs.

\section{Comparison with Equal Slot ArRangement}

To determine the efficacy of the alternate slot arrangement with dummy slots, the pulsating torque is compared between the alternate and equal slot arrangements with dummy slots for 2 coil sides per pole per phase. The equal slot arrangement does not conform to the strategy of suppressing harmonic components of the EMF to minimize torque pulsation. The rotor magnet designs are evaluated by examining the torque pulsation determined by the FEM analysis.

\section{A. Magnet Designs Based on FEM Analysis}

Before a numerical examination of the rotor magnet designs in the equal slot arrangement, the cogging torque is suppressed by using the design techniques of including dummy slots and magnet shifting. The location of dummy slots and the shift angle of magnet pairs can be theoretically determined.

For the equal slot arrangement, 2 dummy slot designs, shown in Figs. 3(b) and (c), are considered. One of the designs establishes an equal distribution of the magnetic reluctance that is periodic for each $7.5^{\circ}$ electrical by introducing a dummy slot at the center of each tooth. It is predicted that the slots enhance the 24th harmonic of the cogging torque and suppress the other harmonics. The design of the stator is designated ESW48. In the other design, 2 dummy slots are constructed on each tooth to achieve a periodic distribution of magnetic reluctance for each $5^{\circ}$ electrical. Thus, the 36th harmonic becomes the dominant component of the cogging torque. The design is designated ESW72.

The dominant harmonics of the cogging torques, which are enhanced by the introduction of dummy slots, are suppressed by shifting magnet pairs. According to (14), the 24th and 36th harmonic components can be suppressed by the adjusting the shift angle $\beta_{\mathrm{m}} / p$ to $1.875^{\circ}(2 i-1)$ and $1.25^{\circ}(2 i-1)$ for a positive integer $i$.

With the design featuring dummy slots, the arc width and the shift angle of magnets are optimized by examining the resulting torque pulsation. Fig. 13 shows the ripple factor of the torque, which is defined as the peak-to-peak value relative to the average, for a magnet arc width $\alpha_{\mathrm{m}}$ and a magnet shift angle $\beta_{\mathrm{m}}$ in the equal slot arrangements with dummy slots for current vector control with $I=5 \mathrm{~A}$ and $\theta_{0}=90^{\circ}$ in (4). The results of the FEM analysis determine the optimal parameters of the magnet designs. The pulsating torque of ESW48 is locally minimized at $\alpha_{\mathrm{m}} / p=71^{\circ}$ and $\beta_{\mathrm{m}} / p=5.625^{\circ}$; this design is designated ESW48M. The arrangement of ESW72 produces a pulsating torque that is

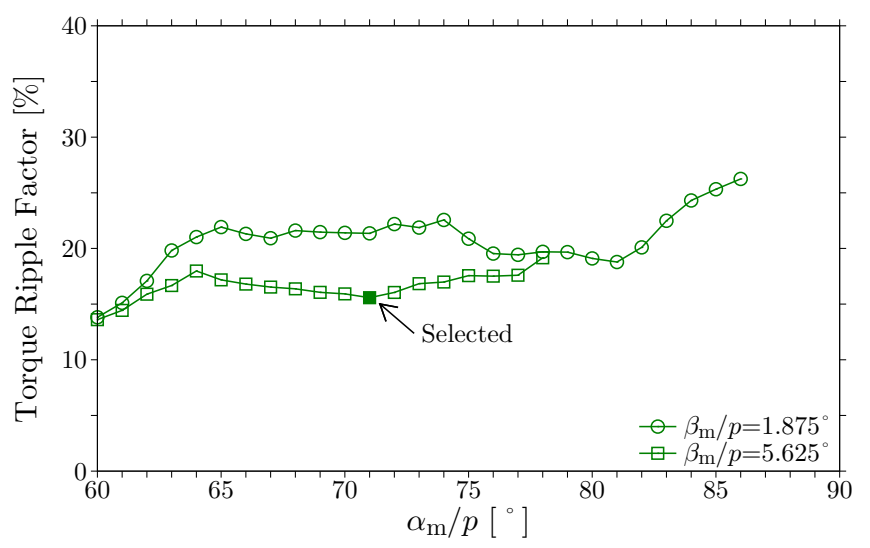

(a) ESW48

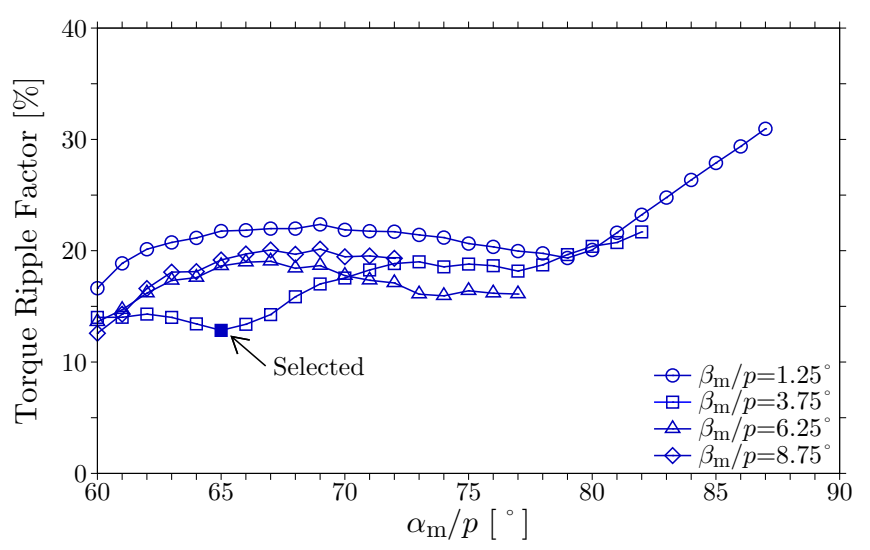

(b) ESW72.

Fig. 13. Ripple factor of torque for a magnet arc width $\alpha_{\mathrm{m}}$ and a magnet shift angle $\beta_{\mathrm{m}}$ in ESW48 and ESW72.

locally minimized at $\alpha_{\mathrm{m}} / p=65^{\circ}$ and $\beta_{\mathrm{m}} / p=3.75^{\circ}$, which is designated ESW72M. These designs suppress the torque pulsation to approximately $15 \%$ of the average torque.

\section{B. Comparison}

The pulsating torque is compared among the various slot winding designs, namely, ESW24, ESW48M, ESW72M, ASW24, and ASW60M. The associated back-EMF, cogging torque, and mutual or ripple torque are examined to confirm the validity of the design method.

The back-EMF in the phase winding at $1500 \mathrm{rpm}$ is shown in Figs. 14(a) and (b) for the slot windings. The design ASW60M almost completely suppresses the 5th, 7th, 11th, and 13th harmonics as desired. Consequently, the 19th harmonic, which is not considered to be reduced, becomes the largest component other than the fundamental harmonic. The design ESW48M significantly suppresses the 7th and 13th harmonics. The remaining 5th and 11th harmonics give rise to the 6th and 12th harmonics of the ripple torque, respectively. In the design ESW72M, the 5th harmonic remains the dominant component, whereas the other harmonics are significantly reduced. The 5 th harmonic is not sufficiently suppressed for the equal slot winding designs. In the rotor magnet designs, the elimination of the 5th harmonic requires a large change in the magnet 


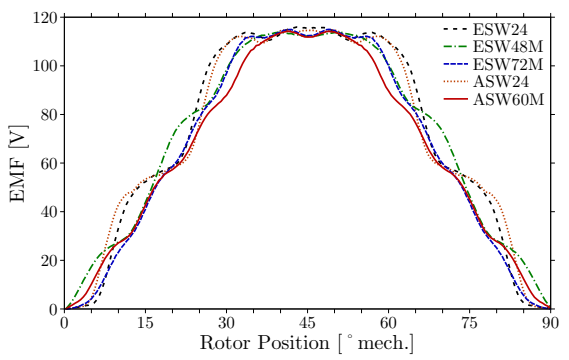

(a) Waveform of back-EMF.

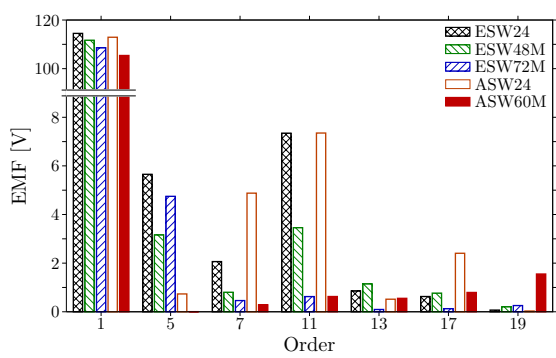

(b) Harmonic components of back-EMF.

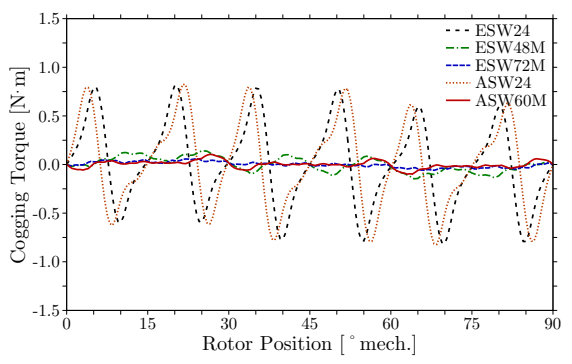

(c) Waveform of cogging torque.

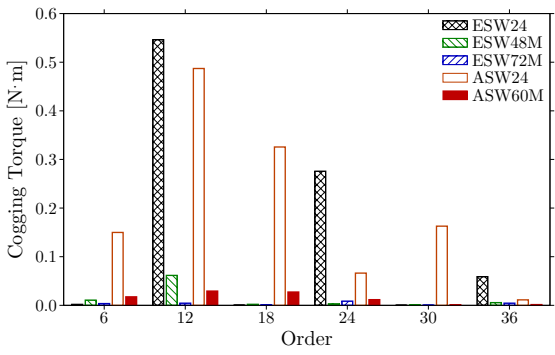

(d) Harmonic components of cogging torque.

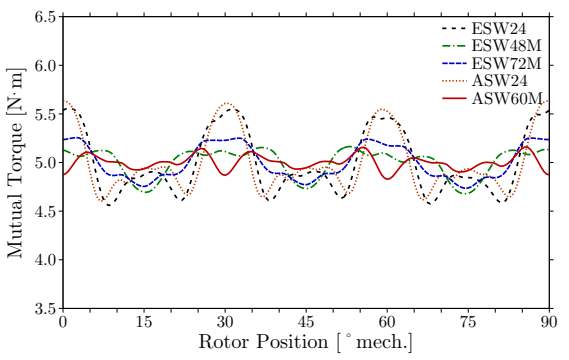

(e) Waveform of mutual torque.

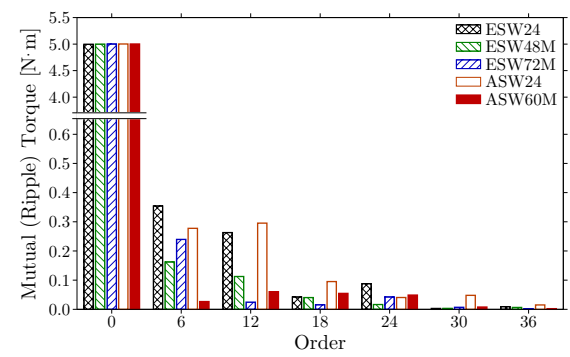

(f) Components of mutual torque.

Fig. 14. Back-EMF in phase winding at $1500 \mathrm{rpm}$, cogging torque, and mutual torque for ESW24, ESW48M, ESW72M, ASW24, and ASW60M. In the mutual torque, the current is fed to produce an average torque of $5.0 \mathrm{~N} \cdot \mathrm{m}$ at the current phase $\theta_{0}=90^{\circ}$ for vector control.

shifting or the magnet width. However, the magnet shift angle and the magnet width are confined to narrow ranges under the design conditions. For this reason, the 5 th harmonic of the EMF cannot be suppressed by the rotor magnet designs.

The cogging torque for the slot winding designs is shown in Figs. 14(c) and (d). Compared with ESW24 and ASW24, the designs ESW48M, ESW72M, and ASW60M produce small cogging torques. This suppression is attributed to the dummy slots and magnet shifting.

The mutual torque and its harmonic component, the ripple torque, for the slot winding designs are shown in Figs. 14(e) and (f). The current is fed to produce an average torque of $5.0 \mathrm{~N} \cdot \mathrm{m}$ at the current phase $\theta_{0}=90^{\circ}$ for vector control. The dominant 6 th and 12 th harmonics are sufficiently reduced in ASW60M, in which the reduction is attributed to the elimination of the corresponding harmonic components of the EMF.

The torque for the slot winding designs is shown in Fig. 15. The current amplitude $I$ is fixed to produce an average torque of $5.0 \mathrm{~N} \cdot \mathrm{m}$ at the current phase $\theta_{0}=90^{\circ}$ for vector control. For the slot winding designs, the required current amplitude is described in Table III. The dummy slots and rotor magnet design techniques substantially reduce the 12 th and 24th harmonics of the torque, which are the dominant components of the pulsating torque in the original design ESW24. However, the 6th harmonic component clarifies the distinction between the equal and alternate slot winding arrangements. The design ASW60M produces the harmonic component of approximately $0.04 \mathrm{~N} \cdot \mathrm{m}$. On the other hand, the 6 th harmonic component remains greater than $0.15 \mathrm{~N} \cdot \mathrm{m}$ in the equal slot winding designs ESW48M and ESW72M. This result is attributed to the 5th harmonic of the EMF, which is not suppressed.

The reduction effects on the back-EMF, cogging torque, and total torque for the slot winding designs are described in Table III. The alternate slot winding arrangement with dummy slots, ASW60M, reduces the ripple factor by approximately $30 \%$ from that of the original design, ESW24. In addition, this design enables the ripple factor to be further reduced by more than $3 \%$ from the equal slot winding designs ESW48M and ESW72M, even though the designs for the equal slot winding arrangement are optimized through the FEM analysis.

\section{CONCLUSION}

This paper proposes a stator design that combines the features alternate slot winding and dummy slots for the selective elimination of harmonic components of the EMF without degenerating the cogging torque to minimize pulsating torque in surface-mounted PM synchronous motors. The alternate slot winding arrangement eliminates a harmonic component of the back-EMF by adjusting the slot angle. However, the alternate slot arrangement decreases the frequency of the cogging torque by half and may aggravate torque pulsation. The dummy slots compensate for the drawback of the alternate slot arrangement. Because the machine design is based on theory, the design method can be applied to various machines in combination with other design techniques and requires little time to design. The alternate slot winding arrangement is proposed for 2 coil sides per pole per phase. This is because the equal slot winding arrangement provides favorable harmonic minimization for more than 2 coil sides per pole per phase. The proposed stator design is applied to a prototype in conjunction with other design techniques for rotor magnets to minimize pulsating torque. The designed motor reduces the ripple factor by approximately $30 \%$ relative to the original value. In addition, the proposed alternate slot winding arrangement is validated by comparison with the equal slot winding arrangement optimized 
TABLE III

BACK-EMF, COGGING TORQUE, AND TOTAL TORQUE FOR THE SLOT WINDING DESIGNS.

\begin{tabular}{lrrrrrr}
\hline \multicolumn{2}{c}{ Back-EMF } & Cogging Torque & \multicolumn{3}{c}{ Total Torque } \\
Design & \multicolumn{1}{c}{ RMS $^{\dagger}$} & \multicolumn{1}{c}{ THD } & Peak to Peak & Current & Average & Ripple \\
\hline ESW24 & $81.5 \mathrm{~V}$ & $11.2 \%$ & $1.62 \mathrm{~N} \cdot \mathrm{m}$ & $5.55 \mathrm{~A}$ & $5.0 \mathrm{~N} \cdot \mathrm{m}$ & $42.9 \%$ \\
ESW48M & $79.2 \mathrm{~V}$ & $7.4 \%$ & $0.29 \mathrm{~N} \cdot \mathrm{m}$ & $5.70 \mathrm{~A}$ & $5.0 \mathrm{~N} \cdot \mathrm{m}$ & $12.9 \%$ \\
ESW72M & $77.4 \mathrm{~V}$ & $12.4 \%$ & $0.12 \mathrm{~N} \cdot \mathrm{m}$ & $5.88 \mathrm{~A}$ & $5.0 \mathrm{~N} \cdot \mathrm{m}$ & $11.4 \%$ \\
ASW24 & $80.0 \mathrm{~V}$ & $10.6 \%$ & $1.65 \mathrm{~N} \cdot \mathrm{m}$ & $5.64 \mathrm{~A}$ & $5.0 \mathrm{~N} \cdot \mathrm{m}$ & $44.6 \%$ \\
ASW60M & $74.9 \mathrm{~V}$ & $10.4 \%$ & $0.20 \mathrm{~N} \cdot \mathrm{m}$ & $6.07 \mathrm{~A}$ & $5.0 \mathrm{~N} \cdot \mathrm{m}$ & $8.9 \%$ \\
\hline
\end{tabular}

$\dagger$ RMS: Root mean square. $\ddagger$ THD: Total harmonic distortion.

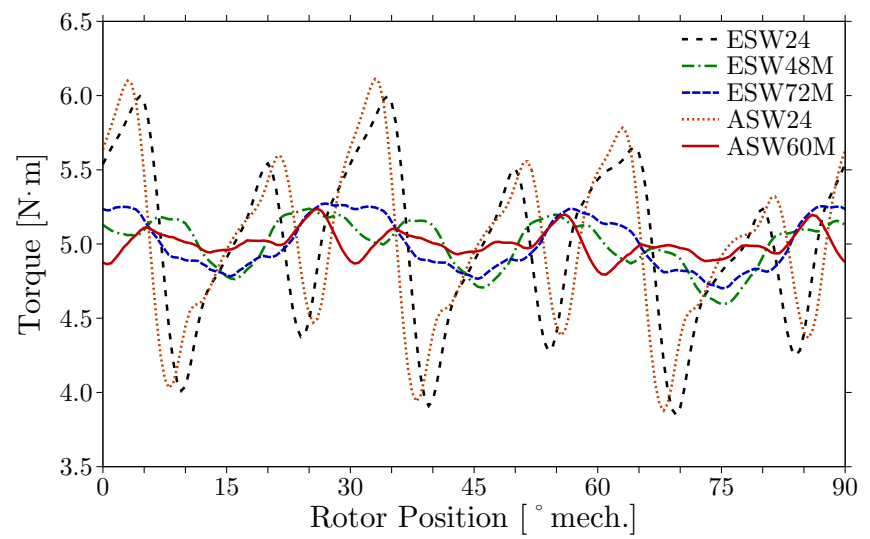

(a) Waveforms.

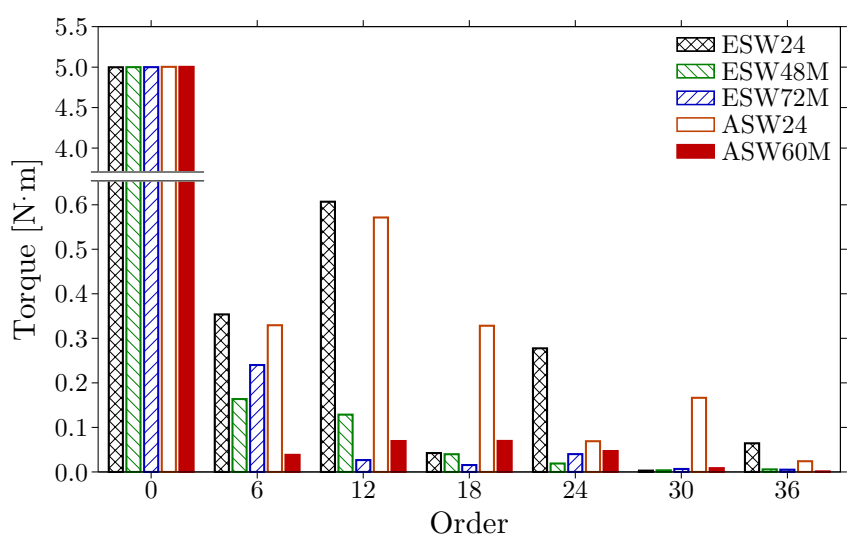

(b) Components.

Fig. 15. Torque for the slot winding designs. The current amplitude is fixed to produce an average torque of $5.0 \mathrm{~N} \cdot \mathrm{m}$ at the current phase $\theta_{0}=90^{\circ}$ for vector control.

through FEM analysis. The machine with the alternate slot winding design exhibits better torque pulsation characteristics than those of the equal slot winding design, despite the numerical optimization of the latter.

\section{ACKNOWLEDGMENT}

The authors would like to thank Yasuhiro Miyamoto of Yaskawa Electric Corporation for fruitful discussions on the design of the prototype. The permanent magnets of the prototype were provided by Hitachi Metals, Ltd. This research was supported in part by a Grant-in-Aid for Scientific Research from Nagasaki University awarded to Yuichi Yokoi.

\section{REFERENCES}

[1] I. R. Smith and J. M. Layton, "Harmonic elimination in polyphase machines by graded windings," in Proc. Inst. Elect. Eng., vol. 110, no. 9, Sep. 1963, pp. 1640-1648.

[2] T. M. Jahns and W. L. Soong, "Pulsating torque minimization techniques for permanent magnet AC motor drives-A review," IEEE Trans. Ind. Electron., vol. 43, no. 2, pp. 321-330, Apr. 1996.

[3] N. Bianchi and S. Bolognani, "Design techniques for reducing the cogging torque in surface-mounted PM motors," IEEE Trans. Ind. Appl., vol. 38, no. 5, pp. 1259-1265, Sep./Oct. 2002.

[4] J. R. Hendershot and T. J. E. Miller, "Design of brushless permanentmagnet machines," Motor Design Books LLC, Florida, USA, 2010.

[5] D. A. Kocabas, "Novel Winding and Core Design for Maximum Reduction of Harmonic Magnetomotive Force in AC Motors," IEEE Trans. Magn., vol. 45, no. 2, pp. 735-746, Feb. 2009.

[6] B. J. Chalmers, "A.C. machine windings with reduced harmonic content," in Proc. Inst. Elect. Eng., vol. 111, no. 11, Nov. 1964, pp. 18591863.

[7] A. Hughes, "New 3-phase winding of low m.m.f.-harmonic content," in Proc. Inst. Elect. Eng., vol. 117, no. 8, Aug. 1970, pp. 2053-7891.

[8] J. Y. Chen and C. Z. Chen, "Investigation of a new AC electrical machine winding," in IEE Proc.-Electr. Power Appl., vol. 145, no. 2, Mar. 1998, pp. $125-132$.

[9] T. Li and G. Slemon, "Reduction of cogging torque in permanent magnet motors," IEEE Trans. Magn., vol. 24, no. 6, pp. 2901-2903, Nov. 1988.

[10] T. Ishikawa and G. Slemon, "A method of reducing ripple torque in permanent magnet motors without skewing," IEEE Trans. Magn., vol. 29, no. 2, pp. 2028-2031, Mar. 1993.

[11] D. C. Hanselman, "Effect of skew, pole count and slot count on brushless motor radial force, cogging torque and back EMF," in IEE Proc.-Electr. Power Appl., vol. 144, no. 5, Sep. 1997, pp. 325-330.

[12] R. Islam, I. Husain, A. Fardoun, and K. McLaughlin, "PermanentMagnet Synchronous Motor Magnet Designs With Skewing for Torque Ripple and Cogging Torque Reduction," IEEE Trans. Ind. Appl., vol. 45, no. 1, pp. 152-160, Jan./Feb. 2009.

[13] Y. Yokoi and T. Higuchi, "Selective Elimination of EMF Harmonics with Stepped Skewing for Ripple Torque Reduction in Surface-Mounted Permanent Magnet Motors," IEEJ J. Ind. Appl., vol. 3, No. 6, pp. 463469, Nov. 2014.

[14] M. Gotou and K. Kobayashi, "An Analysis of the Cogging Torque of a DC Motor and a New Reducing Technique," IEEJ Trans. B, vol. 103, no. 11, pp. 711-718, Nov. 1983 (in Japanese).

[15] K. Kobayashi and M. Gotou, "A New Structure of a Brushless DC Motor with Reduced Torque Fluctuation," IEEJ Trans. B, vol. 105, no. 6, pp. 507-514, June 1985 (in Japanese).

[16] B. Boukais and H. Zeroug, "Magnet segmentation for commutation torque ripple reduction in a brushless DC motor drive," IEEE Trans. Magn., vol. 46, no. 11, pp. 3909-3919, Nov. 2010.

[17] S. M. Jang, et al., "Magnet pole shape design of permanent magnet machine for minimization of torque ripple based on electromagnetic field theory," IEEE Trans. Magn., vol. 47, no. 10, pp. 3586-3589, Oct. 2011.

[18] S. Q. A. Shah, T. A. Lipo, and B. I. Kwon, "Modeling of novel permanent magnet pole shape SPM motor for reducing torque pulsation," IEEE Trans. Magn., vol. 48, no. 11, pp. 4626-4629, Nov. 2012.

[19] Y. Shen and Z. Q. Zhu, "Investigation of permanent magnet brushless machines having unequal-magnet height pole," IEEE Trans. Magn., vol. 48, no. 12, pp. 4815-4830, Dec. 2012.

[20] W. Q. Chu and Z. Q. Zhu, "Investigation of torque ripples in permanent magnet synchronous machines with skewing," IEEE Trans. Magn., vol. 49, no. 3, pp. 1211-1220, Mar. 2013. 
[21] D. Wang, X. Wang, and S. Y. Jung, "Cogging torque minimization and torque ripple suppression in surface-mounted permanent magnet synchronous machines using different magnet widths," IEEE Trans. Magn., vol. 49, no. 5, pp. 2295-2298, May 2013.

[22] T. Liu, S. Huang, J. Gao, and K. Lu, "Cogging torque reduction by slot-opening shift for permanent magnet machines," IEEE Trans. Magn., vol. 49, no. 7, pp. 4028-4031, Jul. 2013.

[23] H. Le-Huy, R. Perret, and R. Feuillet, "Minimization of torque ripple in brushless DC motor drives," IEEE Trans. Ind. Appl., vol. 22, no. 4, pp. 748-755, Jul./Aug. 1986.

[24] R. Carlson, A. Tavares, J. P. Bastos, and M. Lajoie-Mazenc, "Torque ripple attenuation in permanent magnet synchronous motors," in Rec. IEEE Ind. Appl. Soc. Annu. Meet., 1989, pp. 57-62.

Yuichi Yokoi (M'12) was born in Japan in 1984. He received the B.E., M.E., and Ph.D. degrees from Kyoto University, Japan, in 2006, 2008, and 2011, respectively. Since 2011, he has been with the Division of Electrical Engineering and Computer Science, Nagasaki University, Japan as an assistant professor.

His research interests include the technological application of nonlinear dynamics and the design of electrical machines. He is a member of the Institute of Electrical Engineers of Japan, the Institute of Electronics, Information and Communication Engineers, and the Institute of Systems, Control and Information Engineers.

Tsuyoshi Higuchi (M'08) was born in Japan in 1954. He received the B.E., M.E., and Ph.D. degrees from Kyushu University, Fukuoka, Japan, in 1977, 1979 , and 1982, respectively. Since 1982, he has been with the Division of Electrical Engineering and Computer Science, Nagasaki University, Japan, where he is currently a Professor.

His research interests are analysis, design and control of linear motors and rotary motors, such as induction motors, switched reluctance motors and permanent magnet motors. He is a member of the Institute of Electrical Engineers of Japan and the Japan Society of Applied Electromagnetics and Mechanics. 